\title{
Prevalence and Identification of Bovine Ixodid Tick with their Associated Risk Factors in Hosana District, Hadiya Zone Southern Ethiopia
}

\section{Haben Fesseha* and Mesfin Mathewos}

School of Veterinary Medicine, Wolaita Sodo University, Wolaita Sodo, Ethiopia

*Corresponding Author: Haben Fesseha, School of Veterinary Medicine, Wolaita

Sodo University, Wolaita Sodo, Ethiopia.
Received: April 28, 2020

Published: May 22, 2020

(C) All rights are reserved by Haben

Fesseha and Mesfin Mathewos.

\section{Abstract}

A cross-sectional study was conducted from November 2017 to April 2018 with the objectives of assessing the prevalence of bovine ixodid tick with their risk factors in Hosana district, Hadiya Zone. A total of 384 tick samples were collected from the main body parts of cattle of different age, sex, and body condition for parasitological examination. and four genera of ticks were identified. According to the assessment, the overall prevalence of tick infestation was $29.4 \%$. From these ticks genera, Hyalomma takes the highest prevalence (11.9\%) followed by Amblyomma (10.7\%), Boophilus (10.2\%) and Rhipicephalus (9.4\%). The prevalence of tick infestation in poor body condition (72.6\%) was higher as compared to good (14.2\%) and moderate body condition (13.3\%). Besides, the prevalence was higher in old (37.5\%) than young (30.4\%) and adults (28.0\%) age groups of cattle. Moreover, female cattle (30.4\%) were more susceptible than male $(28.6 \%)$ ones. There was a statistically significant $(p<0.05)$ higher tick prevalence in the wet season than dry seasons. However, there was no statistically significant ( $p>0.05$ ) association between tick infestation and age, sex, and body condition. Accordingly, the study showed that the prevalence of ticks is still playing a major role in reducing productivity and cause health problems of cattle in the area which needs a serious collaborative effort and urgent attention.

Keywords: Hosana District; Host Risk Factors; Prevalence; Tick Infestation

\section{Introduction}

Ethiopia is endowed with the largest livestock population in Africa with the estimated domestic animal number of 57.83 million cattle, 28 million sheep, 28.6 million goats, 1.23 million camels, 60.5 million poultry, 2.1 million horses, 0.4 million mules and 7.88 million donkeys representing $45 \%$ of agricultural output/GDP in Ethiopia. Export commodities (meat, live animals, hides and skins as well as drought power, milk production and a source of manure are the main outputs of livestock [1-3].

Ectoparasites are widespread and the most important prevalent constraints to the livestock sector that affect the production and productivity of cattle $[4,5]$. Ticks are among the most common ectoparasites and vectors of important animal diseases on a global scale particularly, in tropical and sub-tropical parts of the world. As ectoparasites ticks are responsible for tick-borne disease, anemia, irritations, skin abrasions, tick toxicosis, tick worry, bite wound, wounds and myiasis and loss of udders, which provides portals of entry for secondary bacterial infection $[6,7]$ and also indirectly act as reservoirs and vectors for a wide range of human and animal pathogens worldwide and thus transmits pathogens such as viruses, bacteria, protozoa and toxins into their hosts $[2,8]$.
Ticks are obligate blood-feeding ectoparasites of vertebrates particularly mammals, birds, and reptiles throughout the world. All ticks spend most of their life cycle away from their hosts, hiding either in soil and vegetation or in the nests of their hosts [9,10]. Ticks are grouped into three families as Ixodidae (hard ticks) with 702 officially recognized species, Argasidae (soft ticks) comprising 193 species, and Nuttalliellidae with a single species. Ixodid ticks pass via four stages in their development: eggs, 6- legged larva, 8-legged nymph, and adult. They are categorized into one-host; two-host or three-host life cycles according to the number of hosts required to complete their lifecycle $[11,12]$.

In Ethiopia, ticks are very common and widely distributed in all agro-ecological zones of the country [13]. They are prominent parasites and competent vectors of pathogens that affect both humans and animals [6] and are usually considered to have more veterinary significance because they negatively affect the health and productivity of domestic animals as a consequence of direct parasitism and disease transmission [9].

The main genera of ticks found in Ethiopia are Ambylomma, Rhipicephalus, Hyalomma and Haemaphysalis, and a subgenus Rhipicephalus (Boophilus). Previous studies documented the pres- 
ence of more than 60 species of ticks in the country including genus Ambylomma (8 spp.), subgenus Boophilus (2 spp.), Haemaphysalis (4 spp.), Hyalomma (9 spp.), Rhipicephalus (15 spp.), Ixodes (1 spp.), Argas (1 spp.) and Ornithodorus (2 spp.) which are reported to have great veterinary and medical importance in Ethiopia. Among these, A. variegatum and Rh (Boophilus). Decoloratus are the most important and widely distributed $[14,15]$. A. coherence, A. gemma, A. lepidium, $H$. marginatum rufipes, $H$. truncatum and $R$. evertsi are also commonly found in Ethiopia [5,6].

In Ethiopia, tick occupies the first place amongst the external parasites and induces a significant economic loss in cattle by the decline of hide and skin quality, reduction of milk yield and increase susceptibility to vector-borne diseases like Babesiosis, Anaplasmosis and Ehrlichiosis in ruminants $[6,15]$. Regardless of losses due to tick infestation in Ethiopia and several researchers reported the prevalence and species identification of ixodid ticks of cattle in different parts of the country. However, there is no work done and up-to-date comprehensive information on the prevalence of tick in cattle in the study area. Hence, the present study was conducted to assess the prevalence of Bovine Ixodid Tick infestation in selected districts of Hadiya Zone.

\section{Materials and Methods}

Study area

The study was conducted in the Hosana district Hadiya zone, Southern Ethiopia. Topographically the zone lies within an elevation range of 1500 to 3000 meters above sea level. The zone has three agro-ecological zones. Highland (23.7\%), Mild-altitude (64.7) and lowland (11.6\%). The annual average temperature of the zone is $22.02^{\circ} \mathrm{C}$ and the mean annual rainfall is $1260 \mathrm{~mm}$ [16].

Study animals and sample size determination

The study animals were cattle of different age and sex that were brought to veterinary clinics and Animal health posts of the selected woredas in the study area. The age, sex, season tick infestation, and body condition scores were recorded according to $[17,18]$. The body condition scores of animals were evaluated during sample collection. and classified as emaciated (poor), moderate (medium) and good based on anatomical parts and the flesh and fat cover at different body parts. Besides, the age of the cattle were categorized into young ( $<3$ years), adult ( $4-6$ years) and old ( $>7$ years) age groups as described by Arnold M and Wilesmith J [19].

Moreover, using an estimated prevalence of 50\%, a 95\% confidence interval (CI), and a 5\% precision or accuracy level, the sample size was calculated to be 384 . The following formula was used to determine the sample size [20]:
$n=Z^{2} \times P(1-P) / d^{2}$

Where, $\mathrm{n}=$ the required sample size, $\mathrm{Z}=$ Confidence level (regular value $=1.96), \mathrm{P}=$ Expected prevalence $(50 \%)$ and $\mathrm{d}=$ Desired absolute precision (0.05).

Study design

A cross-sectional study was conducted from November 2017 to April 2018 in the Hosana district of Hadiya zone. For this study, the woredas were selected using a purposive sampling technique depending upon the agroecology which favors tick infestation while the study animals were selected using simple random sampling.

Study methodology

Tick collection, preservation and identification

Ticks samples were collected after cattle were properly restrained. All visible adult ticks were carefully removed and were collected by forceps and gloved handpicking by a simple random sampling method from different body parts (scrotum, udder, brisket, dewlap, neck, belly/flunk and back, perineal region, tail and other posterior and ventral body parts of the body) of the cattle without damaging their mouthparts following standard tick collection techniques [21,22].

The collected ticks were preserved in $70 \%$ ethyl alcohol in clean, well-stopped glass vials and labeled properly. The identification of the tick was carried out based on their morphological features such as mouthparts, scutum, and color of legs, festoons, presence or absence of posterior groove and marginal spots using a stereoscopic microscope $[12,22]$

\section{Data analysis}

Descriptive data analysis was employed in summarizing the data regarding the prevalence of tick isolated in cattle and associated risk factors including age, sex, body condition, and seasons of the study period. Chi-square test was employed in comparing the prevalence of tick with age, sex, body condition, and seasons of the study period to determine the association of risk factors and prevalence of tick in cattle. In all the analyses, confidence interval (CI) was held at $95 \%$ and $\mathrm{P}<0.05$ was set for statistical significance.

\section{Results}

Tick burden and species identification

Out of 384 cattle examined, $42.2 \%(162 / 384)$ were found to be infested with four different genera of ticks. Hyalomma (11.9\%) takes the largest share in infesting cattle in the study area from all four genera followed by Amblyomma (10.7\%), Boophilus (10.2\%) and Rhipicephalus (9.4\%) (Table 1). 


\begin{tabular}{|c|c|c|}
\hline Ticks genera & Frequency & Proportion \\
\hline Amblyomma & 41 & 10.7 \\
\hline Boophilus & 39 & 10.2 \\
\hline Hyalomma & 46 & 11.9 \\
\hline Rhipicephalus & 36 & 9.4 \\
\hline
\end{tabular}

Table 1: The overall proportion of ticks genera identified in the Hosana district.

Tick infestation in cattle and different risk factors

According to the present study, both sexes of animals were infested with four different types of ticks with a prevalence rate of $30.4 \%$ (55/181) for females and $28.6 \%$ (58/203) for males. The highest infestation rate was observed in old cattle $37.5 \%(40 / 45)$ followed by young $30.4 \%$ (21/69) and adults $28.0 \%$ (77/275). There was no statistically significant difference between in both sex $\left(X^{2}=1.56, p=0.459\right)$ and different age groups $\left(X^{2}=0.15, p=\right.$ 0.697 ) and the prevalence of tick in the study areas (Table 2 ).

In the present study, the season of the study period related to the tick infestation was assessed and a higher prevalence of tick infestation 33.8\% (79/234) was reported during the autumn followed by winter $22.7 \%(34 / 150)$. There was a statistically significant $\left(X^{2}=5.42, p=0.002\right)$ association between the tick prevalence and the season of the study period. Moreover, the body condition wise prevalence of tick was also compared and it was higher in cattle with poor body condition (72.6\%) followed by good body condition (14.2\%) and moderate body condition (13.3\%). There was no statistically significant difference between body conditions score and tick prevalence $\left(\mathrm{X}^{2}=1.032, \mathrm{p}=0.597\right)$ (Table 2).

Out of the total animal, the tick burden (number of ticks) on the cattle was assessed in this study. All cattle were infested with a moderate level of tick burden (100\%) (up to 46 tick) followed by a few (99.1\%) (up to 20 tick) tick burden. Besides, there was a statistically significant difference $\left(X^{2}=36.41, p=0.000\right.$ ) (Table 2). Generally as shown from table 2 , the potential risk factors; age, body condition, and sex did not show any statistically significant associations $(\mathrm{P}>0.05$ ) with the occurrence of the tick prevalence while Tick infestation has shown statistical significance association $(\mathrm{P}<0.05)$ with the season of the study period and tick burden of the cattle.

\begin{tabular}{|c|c|c|c|c|c|c|}
\hline \multicolumn{2}{|c|}{ Risk factor } & Examined Animals & Tick count/infestation & Prevalence (\%) & Chi-square & P-value \\
\hline \multirow[t]{3}{*}{ Age } & Young & 69 & 21 & 30.4 & \multirow[t]{3}{*}{1.56} & \multirow[t]{3}{*}{0.459} \\
\hline & Adult & 275 & 77 & 28.0 & & \\
\hline & Old & 40 & 15 & 37.5 & & \\
\hline \multirow[t]{2}{*}{ Sex } & Male & 203 & 58 & 28.6 & \multirow[t]{2}{*}{0.15} & \multirow[t]{2}{*}{0.697} \\
\hline & Female & 181 & 55 & 30.4 & & \\
\hline \multirow[t]{3}{*}{ Body Conditions } & Poor & 269 & 82 & 72.6 & \multirow[t]{3}{*}{1.032} & \multirow[t]{3}{*}{0.597} \\
\hline & Moderate & 49 & 15 & 13.3 & & \\
\hline & Good & 66 & 16 & 14.2 & & \\
\hline \multirow[t]{2}{*}{ Season } & Winter & 150 & 34 & 22.7 & \multirow[t]{2}{*}{5.42} & \multirow[t]{2}{*}{0.020} \\
\hline & Autumn & 234 & 79 & 33.8 & & \\
\hline \multirow[t]{3}{*}{ Tick Burden } & None & 270 & 0 & 0 & \multirow[t]{3}{*}{36.41} & \multirow[t]{3}{*}{0.000} \\
\hline & Few & 112 & 111 & 99.1 & & \\
\hline & Moderate & 2 & 2 & 100.0 & & \\
\hline
\end{tabular}

Table 2: Potential risk factors for prevalence of bovine ixodid tick infestation in the Hosana district.

\section{Discussion}

In this study period, a total of 384 cattle were examined and the overall prevalence was found to be $42.2 \%$ with four different genera of ticks namely Hyalomma (11.9\%), Amblyomma (10.7\%), Boophilus (10.2\%), and Rhipicephalus (9.4\%). This prevalence was less than the report of Meaza., et al. (23) 211 (91.7\%) in Bahir Dar extensive farms, Kemal., et al. [4] 2024 (75.7\%) in Arbegona District, Southern Ethiopia, Teshome., et al. [24] 270 (70.31\%) in Bish- oftu town, Wogayehu., et al. [25] 68.12\% in the high land of Decha woreda and Shichibi., et al. [2] in Saylem 502 (88.54\%), Gesha 183 (91.50\%) and Masha 149 (78.84\%) Districts of Southern Ethiopia.

In contrast to the current study, a high prevalence of ixodid ticks was reported from different part of Ethiopia by various authors including 82\% [26], 81.25\% [27], 74\% [23] and 65.5\% [28]. Additionally, a higher prevalence of tick infestation in cattle was 
also recorded by Regassa [29] in the eastern parts of Oromia and Ayalew., et al. [30] in central parts of Oromia, respectively. Similarly, the higher finding was reported by de Castro [31] where it was stated that more than $80 \%$ of the cattle studied were ticks-infested. Abera., et al. [32] reported around 95\% tick infestation prevalence in southwestern Ethiopia.

The current study was higher than the previous report of Tiki and Addis [33] with 25.64\% tick infestation prevalence in Holeta district and Zelalem., et al. [34] 146 (38\%) in the Chiro district. The variation in the prevalence rate in the study area might be attributed to the agroecological, animal health practice, the management system within their respective study area, level of awareness of farmers about economic importance tick and tick control strategy.

In the present study, the season of the study period was significantly ( $p=0.002)$ associated with the tick prevalence, and a higher prevalence of tick infestation 33.8\% (79/234) was reported during the autumn followed by winter $22.7 \%$ (34/150). This was in line with the previous report of $[2,10,12,22]$ where the season has a great role in tick reproduction and increases during the rainy season than the dry season in which the larvae of the ticks are very susceptible to temperature increment.

There was variation in sex-based prevalence with higher prevalence was recorded in female $30.4 \%(55 / 181)$ as compared to males $28.6 \%$ (58/203). This finding was in line with the previous findings of Shichibi., et al. [2] 351 (89.77\%), Zelalem., et al. [34] 70 (41.9\%) in Chiro district and Belayneh and Bogale [35] 169 (78.6\%) in Jabitehnan Woreda. In this study, the female prevalence was higher than male cattle due to females stay long years in their farm for dairy purposes in which the probability infesting with tick was more than male mainly kept for fattening (meat purpose) for a short period of time.

The age-wise tick prevalence of the current study showed that a higher (37.5\%) tick burden was recorded in older cattle followed by young $(30.4 \%)$ and adults $(28.0 \%)$. This result in line with the finding of Kemal., et al. [4] with a prevalence of $98.4 \%$. However, this result disagreed with the previous report by Shichibi., et al. [2] with prevalence higher in adult (93.97\%) than young (78.71\%), Meaza., et al. [23] with high prevalence with increasing age interval $(62.7 \%)$ and 251 (85.1\%) and Yalew., et al. [36] with the highest affected young age cattle $56(43.41 \%)$ than other age groups. In the present study, higher tick burden in older animals than the other age groups is probably associated with low immunity and resistance of old animals. Young cattle were managed in the house until they become more strong so that the chance of acquiring the tick was less than adult one which was kept in an outdoor system. Even though there was variation in sex and age, there was no significant association ( $p>0.05$ ) with the prevalence of tick (Table 2).

Regarding body condition, the tick burden was higher in cattle with poor body condition (72.6\%) followed by good body condition (14.2\%) and moderate body condition (13.3\%). This was comparable with the finding of Kemal., et al. [4] where there was higher tick infestation in older cattle than the other groups. This may be because poorly conditioned animals had low resistance to tick infestation and lack enough body capacity to build resistance whereas animals with good body condition showed reasonable combat to the infestation [37]. Moreover, a higher tick burden might be a cause for poor body condition.

In the current study, there was a significant difference $(p<0.05)$ in the prevalence of ticks within the wet and dry season. Similarly, Bedasso., et al. [38] report indicated that there was a statistically significant $(\mathrm{p}<0.05)$ increase in the prevalence of tick in the wet season than the dry season. This was also in agreement with the findings of Alekaw at Metekel ranch which found a tick in a wet season [39]. On the other side, Sileshi., et al. [40] reported that ticks were prevalent on cattle during the study period, although higher tick counts were observed during the rainy than the dry season. However, according to Kemal., et al. [4] there was no considerable difference $(p>0.05)$ in the tick prevalence between the wet and dry season. The most important environmental factors that influence the occurrence of ticks in a biotope include climates such as temperature and relative humidity [9].

In this study, Hyalomma was the most dominant tick genera which accounts for $11.9 \%$ followed by Amblyomma (10.7\%), Boophilus (10.2\%) and Rhipicephalus (9.4\%). According to Wasihun and Doda were also stated that three out of four of our tick genera were prevalent in Ethiopia [41]. This was in contrast to the previous report by Kemal., et al. [4] in Arbegona District, Wasihun and Doda [41] in Humbo district, Ayalew., et al. [30] in central Oromia and Yehualashet., et al. [42] at Haramaya University where Amblyomma was found to be the most abundant tick genera. Besides, Shane., et al. [1] identified Boophilus as the dominant tick in Tiyo District. This could be due to the difference in the season during which the study was conducted $[31,33]$.

\section{Conclusion and Recommendations}

The current study demonstrated that tick infestation was the major challenge in reducing productivity and cause health problems of cattle in the Hosana district with an overall prevalence of $42.2 \%$ revealing ticks are common and important ectoparasite of cattle. A tick has a great production economic impact by causing anemia and weight loss and also decreases the quality of skin and 
hides in the tanneries industries. Poor management systems, lack of awareness about ticks were factors in the distribution of ticks in the areas. In conclusion, good management practices and husbandry system, strategical deworming, awareness creation among cattle owners about bovine tick, application of paddock in the grazing land to break the life cycle of ticks, minimizing frequent contact between different herds and chemical treatment through dipping and spraying to control and minimize the tick burden are important strategies to minimize and control the burden

\section{Competing Interests}

The authors declare that there is no conflict of interest regarding the publication of this paper.

\section{Bibliography}

1. Shane T., et al. "Identification of Tick and Tick Borne HemoParasites in Tiyo District, Arsi Zone, Oromia Region". The Journal of Veterinary Science and Technology 8.418 (2017): 2.

2. Shichibi TH., et al. "Bovine Ixodid Ticks: Prevalence, Distribution and Associated Risk Factors in Saylem, Gesha and Masha Districts, Southern Ethiopia". Advances in Biological Research 11.5 (2017): 265-270.

3. Central Statistical Agency. Central statistical agency agricultural sample survey Rep Livestock Char: Central Statistical Agency (2016): 11-15.

4. Kemal J., et al. "Infestation and Identification of Ixodid Tick in Cattle: The Case of Arbegona District, Southern Ethiopia". Journal of Veterinary Medicine (2016).

5. Misgana N. "Species Diversity and Seasonal Pattern of Ticks and Tick-Borne Pathogens of Cattle in Ada'a and Boset Districts, Central Oromia, Ethiopia". Addis Ababa, Ethiopia: Addis Ababa University (2017).

6. Mideksa K., et al. "Prevalence and Identification of Bovine Ixodide Tick in Dandi District, West Shoa Zone, Oromia Region, Ethiopia" (2017).

7. Nicholson WL., et al. “Ticks (Ixodida) ". Medical and veterinary entomology: Elsevier (2019): 603-672.

8. Jongejan F and Uilenberg G. "The global importance of ticks". Parasitology 129.1 (2004): S3-S14.

9. Latif A and Walker A. "An introduction to the biology and control of ticks in Africa". ICTTD-2 project (2004): 1-29.
10. Wall R and Shearer D. "Veterinary Ectoparasites: Biology, Pathology and Control”. Blackwells Science Ltd. Oxford (2001).

11. Ellse $L$ and Wall R. "The use of essential oils in veterinary ectoparasite control: a review". Medical and Veterinary Entomology 28.3 (2014): 233-243.

12. Wall RL and Shearer D. "Veterinary ectoparasites: biology, pathology and control". John Wiley and Sons (2008).

13. Kumsa B., et al. "Molecular detection of piroplasms in ixodid ticks infesting cattle and sheep in western Oromia, Ethiopia". Tropical Animal Health and Production 46.1 (2014): 27-31.

14. Abebaw G. "Seasonal dynamics and host preference of Boophilus decoloratus on naturally infested cattle in Jimma zone, south western Ethiopia”. Ethiopian Veterinary Journal 18.1 (2004): 19-28.

15. Moges N., et al. "Hard ticks (Ixodidae): species composition, seasonal dynamics and body site distribution on cattle in Chilga District, Northwest Ethiopia". Asian Journal of Agricultural Sciences 4.5 (2012): 341-345.

16. Hadiya Zone Statistical Agency. Basic Geographic Information, Report on Department of Hadiya Zone Finance and development, Southern Nations, Nationalities and Regional State (SNNRS). (2010): 2.

17. Nicholson M and Butterworth MH. "A guide to condition scoring of zebu cattle: ILRI (aka ILCA and ILRAD) (1986).

18. Soares F and Dryden GM. "A body condition scoring system for Bali cattle". Asian-Australasian Journal of Animal Sciences 24.11 (2011): 1587-1594.

19. Arnold M and Wilesmith J. "Estimation of the age-dependent risk of infection to BSE of dairy cattle in Great Britain". Preventive Veterinary Medicine 66.1-4 (2004): 35-47.

20. Thrusfield M. "Veterinary Epidemiology". $3^{\text {rd }}$ edition. London, UK: Blackwell Science Ltd (2005): 182-189.

21. Sharma A., et al. "Molecular prevalence of Babesia bigemina and Trypanosoma evansi in dairy animals from Punjab, India, by duplex PCR: a step forward to the detection and management of concurrent latent infections". BioMed Research International (2013): 1-8.

22. Walker AR. "Ticks of domestic animals in Africa: a guide to identification of species: Bioscience Reports Edinburgh (2003). 
23. Meaza G., et al. "Determination of the prevalence of ixodid ticks of cattle breeds, their predilection sites of variation and tick burden between different risk factors in Bahir Dar, Ethiopia”. Global Veterinaria 13.4 (2014): 520-529.

24. Teshome T., et al. "Prevalence and Species Composition of Ticks Infesting Cattle In and Around Bishoftu Town, Oromia Region, Ethiopia (2016).

25. Wogayehu Y., et al. "Epidemiological Study of Ticks and their Distribution in Decha Woreda of Kafa zone, SNNPRS". International Journal of Research 7.6 (2016): 7-19.

26. Tamerat N., et al. "Identification and prevalence of ixodid tick in bovine at Bedele district, Oromiyia Regional State, Western Ethiopia". Journal of Parasitology and Vector Biology 7.8 (2015): 156-162.

27. Alemu G., et al. "Prevalence of ixodid ticks on cattle in Northwest Ethiopia”. Acta Parasitologica Globalis 5.2 (2014): 139145.

28. Wolde A and Mohamed A. "Prevalence of ixodid ticks on Bovine in Soddozuria districts, Wolaita Zone, Ethiopia”. Acta Parasitologica Globalis 5.3 (2014):188-197.

29. Regassa A. "The use of herbal preparations for tick control in western Ethiopia". Journal of the South African Veterinary Association 71.4 (2000): 240-243.

30. Ayalew T., et al. "Ixodid ticks infesting cattle in three agroecological zones in central Oromia: species composition, seasonal variation, and control practices". Comparative Clinical Pathology 23.4 (2014):1103-1110.

31. De Castro J. “Tick survey, Ethiopia. A survey of the tick species in Western Ethiopia, including previous findings and recommendations for further tick surveys in Ethiopia (1994).

32. Abera M., et al. "Survey of ixodid ticks in domestic ruminants in Bedelle district, Southwestern Ethiopia". Tropical Animal Health and Production 42.8 (2010): 1677-1683.

33. Tiki B and Addis M. "Distribution of ixodid ticks on cattle in and around Holeta town, Ethiopia". Global Veterinaria 7.6 (2011): 527-531.

34. Zelalem A., et al. "Prevalence of Bovine Hard Ticks in Chiro District, West Hararghe Zone, East Oromiya". Acta Parasitol Globalis 7.2 (2016): 66-73.
35. Belayneh N and Bogale B. "Prevalence of Ixodid Ticks on Cattle in and Around Jabitehnan Woreda, North Western Ethiopia”. Acta Parasitologica Globalis 7.3 (2016): 121-125.

36. Yalew A., et al. "Identification of Major Ixodid Ticks on Cattle in and Around Haramaya Town, Eastern Hararghe, Ethiopia”. Acta Parasitologica Globalis 8.1 (2017): 09-16.

37. Manan A., et al. "Prevalence and Identification of Ixodid". Ministry of Economic Development and Cooperation Survey of Livestock and Fisheries Development. Agricultural Development Department, Livestock Team, Addis Ababa, Ethiopia (2007).

38. Bedasso M., et al. "Species composition, prevalence and seasonal variations of ixodid cattle ticks in and around Haramaya town, Ethiopia”. Full Length Research Paper 6 (2014): 131137.

39. Alekaw S. "Distribution of ticks and tick-borne diseases at Metekel Ranch". The Ethiopian Veterinary Journal 4 (1998): 40-59.

40. Sileshi M., et al. "A synthesis review of ixodid (Acari: Ixodidae) and argasid (Acari: Argasidae) ticks in Ethiopia and their possible roles in disease transmission". Ethiopian Veterinary Journal 11 (2007): 1-24.

41. Wasihun P and Doda D. "Study on prevalence and identification of ticks in Humbo district, Southern Nations, Nationalities, and People's Region (SNNPR), Ethiopia". Journal of Veterinary Medicine and Animal Health 5.3 (2013): 73-80.

42. Yehualashet T., et al. "Preliminary Observation on Ticks: Seasonal Dynamics and Resistance of Three Indigenous and Three Cross-Bred Cattle in Ethiopia". Bulletin of Animal Health and Production in Africa 43.2 (1995): 105-114.

\section{Assets from publication with us}

- Prompt Acknowledgement after receiving the article

- Thorough Double blinded peer review

- Rapid Publication

- Issue of Publication Certificate

- High visibility of your Published work Website: www.actascientific.com/

Submit Article: www.actascientific.com/submission.php Email us: editor@actascientific.com Contact us: +919182824667 